\title{
Quantitative Modeling Analysis of the Effect of Cluster Effect on Sports Economy
}

\author{
Xiuying Han \\ College of physical education, Shandong University of Finance And Economics, Jinan Shandong 250014, \\ China
}

Keywords: Cluster Effect, Sports Economy, Impact, Quantitative Modeling, Analysis

\begin{abstract}
Holding large-scale sports activities can bring great significance and impact to host cities and even the entire country. Through the holding of large-scale sports activities, can effectively enhance the city and national reputation. Large-scale sports activities can have a positive impact on the economic development of the host cities through investments, increasing external and effective demands, and enhancing the visibility of host cities and countries. In this paper, we construct a quantitative model to analyze the effect of cluster effects on the economy of the sport.
\end{abstract}

\section{Introduction}

Holding large-scale sports activities can bring great significance and impact to host cities and even the entire country. By organizing large-scale sports activities, it can effectively enhance the city and country's reputation, increase external investment and increase effective external demand. However, corresponding to the positive impact of organizing large-scale sports activities, the liabilities for infrastructure construction due to the holding of large-scale sports activities will also increase correspondingly. Excessive investment pressure will adversely affect the local economic development. It is for these reasons that we should pay more attention to the analysis and study of the impact of large-scale sports activities on the local economy, find the shortcomings and deficiencies, take appropriate measures to correct the deviations in time, maximize the positive impact of large-scale sports activities on the economy, and avoid side effects as much as possible produce.

In general, large-scale sports activities as the middle part of the Games to achieve the related industries and industry-related influence, and promote the changes associated with the industry. According to the input-output model of the United States before, the holding of large-scale sports events such as the Olympic Games can obviously enhance the city's popularity and influence, effectively increase employment opportunities, and actively promote the development of related industries and obtain greater economic benefits. The scholars in our country compared the Shanghai World Expo with the Beijing Olympic Games by using the investment multiplier method to analyze their contribution to the national economy and concluded that the total economic impact of the Beijing Olympic Games totaled 150 billion yuan and analyzed the investment in the Beijing Olympic Games Concerned about the large-scale sports activities after the end of related facilities and equipment to meet the needs of local economic development.

However, if host countries invest too much in infrastruc- ture in infrastructure to organize the sport, they may easily adversely affect the local economy. Therefore, it is important to analyze the economic impact of large-scale sports activities in host countries and host cities, adopt corresponding policies so that large-scale sports activities can give full play to their positive roles and minimize their negative effects, which are of great importance to host countries and host cities significance.

\section{The Proposed Methodology}

Study on the Economic Influence of Large - scale Sports Activities. The impact of large-scale sports activities on the industry refers to the games as an intermediary to trigger changes in related industries and lead to changes in the industrial sector directly related to them. 
Using the input-output model, the American Institute for Economic Research conducted a study of the economic impact of the Olympic Games in Southern California in 1984 and found that the Olympic Games brought about 2.3 billion U.S. dollars in revenue and added 73,357 jobs. Humphreys and Michael improved the above model to conclude that the economic benefits of the Atlanta Olympic Games were 5.1 billion U.S. dollars and employment opportunities were 77,026.

PapanikosBalfousia Savva used the macroeconomic multiplier method to study the Athens Olympic Games and found that the Olympic Games generated more jobs. Zhang Shixian and Ma Li compared the effect of the Beijing Olympic Games and the Shanghai World Expo on the economy by using the investment multiplier method, in which the total impact on Beijing was 150 billion yuan.

In previous studies, the macroeconomic model, input-output model and cGE model were mostly used to analyze the economic impact of large-scale sports activities.

Input-output model. Both input-output model and CGE model are suitable for studying the impact of macro-economy. However, CGE model has the following advantages over input-output model: First, input-output model does not introduce price adjustment mechanism. The CGE model introduces price adjustment mechanisms and organically combines production and demand, international trade and prices. When the economy is under a sudden impact, we can comprehensively examine the impact of the impact on various aspects of the economy, structure, and relative prices, not just local ones. Second, the CGE model replaces many linear functions in traditional input-output models with nonlinear functions, overcomes the shortcomings that the econometric methods are limited to the macroeconomic aggregates, and makes up for the fact that the input-output method places too much emphasis on structural rigidity Caused by the lack of. Third, the data needed by the CGE model is even more complicated than the input-output analysis. It analyzes not only the industry but also individual and government decisions that are beyond the input-output analysis.

CGE model advantages. In general, there are mainly three models for studying the economic impact of large-scale sports activities: input-output model, macroeconometric model and CGE model.

The macroeconomic econometric model is generally applicable to economic analysis under a planned economy and does not apply to a comprehensive assessment of economic policies in complex contexts. By analyzing and studying the decentralized optimization process of the system, the overall maximization goal can be achieved. Therefore, under the CGE model, the economic behavior of consumers and producers can be made more realistic and reliable, and the process and result of economic activities and effects of large-scale sports activities can be revealed more deeply.

In general, the CGE model is more suitable for studying the economic impact of large-scale sport activities than the above two models. This article will use the CGE model as a research method to analyze the role of large-scale sports activities in regional and even national economies, enrich and deepen related research and provide more adequate theoretical support for the organization of large-scale sports activities.

CGE Modeling of Sports Economy. The CGE model can determine the balance adjustment mechanism of the macro-account through different assumptions on the macro-constraints. According to different economic realities and macroeconomic theory, different macro assumptions can be produced and different closure principles can be chosen, leading to different economic adjustment mechanisms and different calculation results. China's economic operation system is different from that of other countries, making the foreign CGE model can not be applied directly to the economic impact analysis of China's holding of large-scale sports activities. In this paper, the State Council Development Research Center and the World Bank to develop the DRc-CGE model as a prototype, the closed-model module has been modified, can be used to study the Olympic Games and other large-scale sports activities on the extent of the industry.

When balancing government and international trade receipts and expenditures, we analyze the government-led investment behavior and adopt various tax rates, government spending and transfer payments to exogenous students to save the government's savings.

In the analysis of the economic impact of large-scale sports activities, investment is mainly concentrated in the construction of venues and other infrastructure, which will make investment 
concentrate in certain industries, leaving other industries to lose some development opportunities. In addition, part of the investment is through the issuance of bonds to raise funds to enterprises and the public. This will generate immediate and intertemporal crowding-in effects on the investment behavior of enterprises and on the consumption of residents, resulting in a reduction in corporate investment or household consumption, which will negatively affect the economy influences. This paper adds three variables of government bonds and corporate bonds issued to enterprises and the public in the closed module so as to more accurately describe the impact of the Olympic economy on various industries.

Under macroscopic closure conditions, the CGE model can be expressed as the following formula:

$\mathrm{S}=\mathrm{GR}-\mathrm{TR}-\mathrm{GExp}-\mathrm{GI}$

Among them, S represents the central government's total savings, GR represents the total revenue of the central government, TR represents the total government transfer payments, GExp represents the government spending, and GI represents the government's total investment in large-scale sports activities.

$\mathrm{S}=\Sigma \mathrm{XE}^{*} \mathrm{WPE} * \mathrm{ER}-\Sigma \mathrm{XM} * \mathrm{WPM} * \mathrm{ER}$

Among them, XE said the number of imports of related products, WPE said the international prices of related products, ER said the exchange rate of foreign exchange, the number of XM related products, WPM also said the international prices of related products.

$\mathrm{TI}=\mathrm{TS}+\mathrm{I}$

$\mathrm{S}=$ HHInc+HHExp-HHTR-HI

$\mathrm{S}=\mathrm{CY}-\mathrm{CTax}-\mathrm{HI}$

Here, TI represents total investment, TS is total savings, I represents investment in large-scale sporting activities, CY is corporate income, and CTax is corporate income tax.

Taking the Olympic Games held in 2008 as an example, the direct investment in the Olympic Games is about 134.8 billion yuan. According to the relevant projections, the investment in the Olympic venues is 28 billion yuan and the subsequent investment in infrastructure construction is 106.8 billion yuan. In this one, Beijing municipal government has accepted about $90 \%$ of the investment, that is 25 billion yuan of Olympic venues in Beijing, the remaining $10 \%$ of the investment is for the construction of Qingdao, Shenyang and other Olympic venues for infrastructure, in addition Including 106.8 billion yuan of follow-up infrastructure construction costs. According to the data, it can be found that the indirect costs incurred during the construction of venues are about 106.8 billion yuan, of which about $30 \%$ is the funds for the pre-Olympic Games with an amount of about 30 billion yuan. This part of the expenditure is directly used in Beijing as a preparation cost. At the same time, the state issued bonds to support the hosting of the Olympic Games.

At the same time, we can continue to study and conclude the relevant corporate bonds issued for the Olympic Games. The issuance of these bonds can also be divided into direct investment and indirect investment according to the nature. Summarize the previous estimates and the total bond issuance to figure out the amount of corporate bonds used for the Olympics each year.

At the same time, based on the information of the previous Olympic Games, we can analyze and judge the number of tourists during the Olympic Games and related tourism revenue, and draw the conclusion that the total number of tourists during the Beijing Olympic Games and the total tourism consumption income will reach 600,000 person-times and 5 billion U.S. dollars About $85 \%$ of Olympic tourism foreign exchange earnings will flow into host cities of the Olympic Games, and the remaining $15 \%$ will flow to other relevant regions and cities. Through the above analysis, it can be found that there were about 5 billion U.S. dollars of foreign exchange earnings in the 2008 Olympic Games in Beijing, of which about 4.25 billion U.S. dollars were flowing into Beijing's foreign exchange earnings. The remaining about 750 million U.S. dollars flowed into the foreign exchange earnings of other relevant regions and cities.

Overall, the hosting of large-scale sports events, including the Beijing Olympic Games, can effectively promote the economic development in the relevant regions and countries. This is mainly due to the multiplier effect of large-scale sports activities that can directly or indirectly drive the 
development of many related industries, This includes transportation, real estate, construction, catering and accommodation, leasing and goods services, as well as postal services.

According to the simulation results, with the Olympic Games having many positive effects on the economy, the government should also give full attention to the possible rapid decline of some industries after the Olympic Games is over. This will not be conducive to the sustainable and coordinated development of the industry and to economic growth forming damage. The government can speed up industrial restructuring in Beijing by means of the Olympics and continue to increase the proportion of the secondary and tertiary industries so that the finance, the information industry, construction and transportation industries will become more and more the pillar industries in Beijing and increase their input.

\section{Conclusion}

Through the research, we can find that organizing large-scale sports activities can effectively enhance the reputation of cities and even countries, enhance the vitality of the economy in the region and effectively stimulate economic investment, which has then also obviously promoted the economic development. In this paper, by revising the closed module in the original model and focusing on the actual situation and development characteristics of our country, the CGE model after the amendment is used to analyze and study the impact and impact of the large-scale sport activities on China's economy. To achieve the economic effect of the dual regional recursion analysis and further enrich the analysis of the economic impact of holding large-scale sports activities in China. Through the actual simulation of the relevant models, we can study the active role of holding large-scale sports activities in our country in promoting the development of the regional economy, promoting the employment of related industries and driving the development of related industries.

\section{References}

[1]. Næss, H.E., 2017. Investment Ethics and the Global Economy of Sports: The Norwegian Oil Fund, Formula 1 and the 2014 Russian Grand Prix. Journal of Business Ethics, pp.1-12.

[2]. Wang, Y., Li, J. and Wang, H.H., 2017. Cluster and cloud computing framework for scientific metrology in flow control. Cluster Computing, pp.1-10.

[3]. Folland, J.P., Allen, S.J., Black, M.I., Handsaker, J.C. and Forrester, S.E., 2017. Running technique is an important component of running economy and performance. Medicine and science in sports and exercise, 49(7), p.1412.

[4]. Huang, W., Wang, H., Zhang, Y. and Zhang, S., 2017. A novel cluster computing technique based on signal clustering and analytic hierarchy model using hadoop. Cluster Computing, pp.1-8.

[5]. Li, Y., 2017. Research on the Development of Education Level of University Sports Aesthetics Based on AHP. Eurasia Journal of Mathematics Science and Technology Education, 13(8), pp.5133-5140.

[6]. Fu, H., 2017. 108. System Difficulties and System Design of "Combination of Sports and Education” under the Background of Game Theory and Data Fusion. Boletín Técnico, ISSN: 0376-723X, 55(17). 